\title{
Diving Medicine: A Review of Current Evidence
}

\author{
James H. Lynch, MD, MS, and Alfred A. Bove, MD, PhD
}

Recreational scuba diving is a growing sport worldwide, with an estimated 4 million sport divers in the United States alone. Because divers may seek medical care for a disorder acquired in a remote location, physicians everywhere should be familiar with the physiology, injury patterns, and treatment of injuries and illnesses unique to the underwater environment. Failure to properly recognize, diagnose, and appropriately treat some diving injuries can have catastrophic results. In addition, recreational dive certification organizations require physical examinations for medical clearance to dive. This article will review both common and potentially life-threatening conditions associated with diving and will review current evidence behind fitness to dive considerations for elderly divers and those with common medical conditions. (J Am Board Fam Med 2009;22:399-407.)

Recreational scuba diving is a growing sport across the globe. Worldwide, the number of annual diving certifications has tripled during the past 20 years. ${ }^{1}$ In the United States alone there are an estimated 4 million sport divers. ${ }^{2}$ Apart from the coastlines, recreational diving takes place in lakes and quarries throughout the country, and divers may present to their local emergency departments or office practices with injuries or illnesses unique to diving and the underwater environment. Because of the popularity of diving in tropical waters and the ease of travel, divers may seek medical care for a disorder acquired in a remote and often unfamiliar location. Failure to properly diagnose and appropriately treat some diving injuries can result in catastrophic outcomes, particularly those involving the brain and spinal cord. In addition, more than ever before, patients of all ages are seeking medical clearance to dive from their primary care physicians, who must be aware of recommendations for fitness to dive. These

This article was externally peer reviewed.

Submitted 14 May 2008; revised 5 November 2008; accepted 21 November 2008.

From the 5th Special Forces Group, United States Army, Fort Campbell, KY (JHL); and Section of Cardiology, Temple University School of Medicine, Philadelphia, PA (AAB).

Funding: none.

Conflict of interest: none declared.

Disclaimer: The views expressed in this manuscript are those of the authors and do not reflect the official policy or position of the Department of the Army, Department of Defense, or the U.S. Government.

Corresponding author: James H. Lynch, MD, MS, DeWitt ACH, Fort Belvoir, VA 22060 (E-mail: james.h.lynch@ us.army.mil). include some controversial topics in diving medicine, which will be reviewed in this manuscript.

\section{Pressure Environment}

The most significant environmental exposure in diving is the increased ambient pressure. Underwater, pressure increases in a linear fashion with depth (Table 1). ${ }^{3}$ Exposure to increased pressure can result in several pathophysiologic changes. One is related to compression and expansion of gas according to Boyle's Law; another is related to increased content of dissolved inert gas in blood and tissues according to Henry's law. ${ }^{3}$

\section{Ear and Sinus Barotrauma}

Although pulmonary barotrauma receives much attention because of the seriousness of its sequelae, barotrauma to the ears and sinuses is a far more common and potentially debilitating injury for divers. Barotrauma is defined as the tissue damage that results from the inability of the body to equalize pressure in a gas-filled space (eg, the middle ear). During ascent and descent, the body is exposed to changes in ambient pressure. According to Boyle's Law, as ambient pressure increases during descent, the volume of gas-filled space decreases. In the ear, for example, the tympanic membrane is deflected inward to the point of rupture unless air is allowed to enter the middle ear via the Eustachian tube. ${ }^{4}$ Middle ear barotrauma ("middle ear squeeze") is the most common diving injury, occurring in $30 \%$ of first-time divers and $10 \%$ of 
Table 1. Effects of Depth on Ambient Pressure

\begin{tabular}{lccc}
\hline $\begin{array}{l}\text { Sea Water } \\
\text { (feet) }\end{array}$ & $\begin{array}{c}\text { Absolute } \\
\text { Pressure } \\
\text { (atm) }\end{array}$ & $\begin{array}{c}\text { Mercury } \\
(\mathrm{mm})\end{array}$ & $\begin{array}{r}\text { Pounds per } \\
\text { Square Inch }\end{array}$ \\
\hline 0 (sea level) & 1 & 760 & 14.7 \\
33 & 2 & 1520 & 29.4 \\
66 & 3 & 2280 & 44.1 \\
99 & 4 & 3040 & 58.8 \\
132 & 5 & 3800 & 73.5 \\
\hline
\end{tabular}

experienced divers. It manifests as acute onset of ear pain and is sometimes associated with vertigo and conductive hearing loss. Clinical findings range from injection of the tympanic membrane to hemotympanum with or without ruptured tympanic membrane. ${ }^{5}$

Sinus barotrauma ("sinus squeeze") is another relatively common diving injury usually resulting from transient nasal pathology or chronic sinusitis. Blockage of the sinus ostium may cause a relative negative pressure in a sinus cavity during descent. This causes engorgement with mucosal edema and can result in bleeding into the sinuses. Sinus barotrauma manifests as acute onset of facial pain with epistaxis. ${ }^{6}$ Other types of barotrauma include barodontalgia ("tooth squeeze"), inner ear barotrauma, and mask squeeze. Treatment for both sinus and middle ear barotrauma includes the use of decongestants and analgesics. Systemic antibiotics for prophylactic treatment of otitis media may be considered in middle ear barotrauma with tympanic membrane perforation. Tympanic membrane rupture should be allowed to completely heal before diving again.

Prevention of these common diving injuries consists primarily of careful attention to pressure equilibration and a slow, feet-first descent. The use of nasal and/or systemic decongestants, such as oxymetazoline and pseudoephedrine, before diving may be helpful; however, they must be used with caution to avoid the rebound effect sometimes associated with a reverse block during ascent at the end of the dive. ${ }^{7}$ Prevention of otic barotrauma is best accomplished through the use of a Valsalva maneuver during descent. Explanation of this maneuver should be part of the diving evaluation. When performing fitness to dive evaluations, the primary care physician must consider the risk of ostial insufficiency from upper respiratory infec- tion, rhinosinusitis, or other conditions that will put a patient at risk for barotrauma when diving. ${ }^{8}$

Inner ear barotrauma is a condition related to middle ear barotrauma. Forceful attempts to equalize the middle ear with the Valsalva maneuver may elicit a pressure gradient between the middle ear and the perilymph of the inner ear large enough to rupture the round or oval window, causing perilymph leakage. This condition presents as acute sensorineural hearing loss, tinnitus, and vertigo. The treatment is not recompression therapy but rather bed rest, head elevation, avoidance of straining, and referral to an otolaryngologist. A detailed dive history is helpful when distinguishing inner ear barotrauma from inner ear decompression sickness (DCS; discussed later). ${ }^{4}$

\section{Pulmonary Barotrauma}

According to Boyle's Law, during ascent, as ambient pressure is reduced, gas inside the lungs expands. If a diver breathing compressed air at depth does not allow the compressed air in the lungs to escape by exhaling, or if air empties slowly from a lung segment because of obstructive pulmonary conditions, then the gas expands during ascent as ambient pressure falls, causing alveoli to rupture. This air under pressure then escapes the alveoli and rushes into surrounding tissues, resulting in mediastinal or subcutaneous emphysema or pneumothorax. In the most severe cases, air will enter the bloodstream via pulmonary veins, traveling through the left heart as an arterial gas embolism (AGE). These air bubbles distribute throughout the arterial circulation and reach the brain where they occlude bloodflow, compromise the blood-brain barrier, and result in stroke-like events. ${ }^{9}$ Almost all cases of AGE present within 5 minutes of ascent and manifest as gross neurologic deficits, including stupor; bilateral or unilateral motor and sensory changes; unconsciousness; visual disturbances; vertigo; convulsions; and, in approximately $5 \%$, complete cardiovascular collapse (Table 2). ${ }^{10}$

Of note, the greatest change in lung volume per change in depth occurs nearest the surface. Therefore, it is possible for divers breathing compressed air in a pool as shallow as 4 feet to develop pulmonary barotrauma if they ascend to the surface while holding their breath at maximum lung volume. ${ }^{11}$ Treatment of AGE consists of advanced cardiac life support, $100 \%$ oxygen, hydration, and immediate 
Table 2. Presenting Signs and Symptoms in Patients with Arterial Gas Embolism

\begin{tabular}{lc}
\hline Sign or Symptom & Percentage \\
\hline Stupor or confusion & 24 \\
Coma without seizures & 22 \\
Coma with seizures & 18 \\
Unilateral motor deficits & 14 \\
Visual disturbances & 9 \\
Vertigo & 8 \\
Unilateral sensory deficits & 8 \\
Bilateral motor deficits & 8 \\
Collapse & 4 \\
\hline
\end{tabular}

Reproduced with permission from Neurologic Complications of Scuba Diving from the June 1, 2001 issue of American Family Physician. Copyright (C) 2001 American Academy of Family Physicians. All Rights Reserved.

recompression using the US Navy Diving Manual Table 6 algorithm, which is a standard protocol that involves recompression to 60 feet in a hyperbaric chamber while breathing oxygen. ${ }^{10}$ The majority of individuals with AGE fully recover with prompt recompression therapy. ${ }^{9}$

\section{Decompression Sickness}

DCS is caused by injury due to bubble formation in blood and tissues. As ambient pressure increases at depth, the partial pressures of inspired gases increase proportionately. Inert gas-primarily nitrogen-is dissolved in tissues, creating in the body a supersaturated state; if ascent is too rapid, the dissolved nitrogen in the blood and tissues will become supersaturated and form bubbles that cause tissue injury through mechanical effects, vascular occlusion, and activation of the clotting cascade and inflammatory mediators. Bubbles are often detected initially in the venous system and pose a further risk for systemic injury by entering the arterial circulation through a patent foramen ovale (PFO), which produces a right-to-left cardiac shunt. Bubbles entering the arterial circulation via a shunt produce symptoms similar to AGE. ${ }^{12}$ The incidence of DCS among recreational scuba divers is approximately 2 to 3 cases per 10,000 dives. ${ }^{13}$ As could be predicted by the pathophysiology, DCS may manifest with a wide array of signs and symptoms and is typically classified into either type I or type II.

Type I (nonsystemic or musculoskeletal) DCS is characterized by the absence of neurologic and other systemic symptoms and usually manifests as musculoskeletal symptoms, such as pain that is often dull or throbbing and poorly localized around a joint - the shoulder and elbow being the most common sites. Skin rash and pruritis are common cutaneous manifestations; less common is cutis marmorata or skin marbling. This condition, which has been reportedly associated with $\mathrm{PFO}$, may be a harbinger of more serious symptoms that could require recompression therapy. ${ }^{14}$ Type I DCS usually presents soon after the dive; $95 \%$ of people affected have onset of pain within 6 hours of surfacing. Joint pain is rapidly relieved with recompression therapy. Cutaneous manifestations usually resolve spontaneously in 12 to 24 hours. The treatment for type I, or musculoskeletal, DCS is recompression using US Navy Diving Manual Table 6 algorithm. ${ }^{15}$

Type II (neurologic or systemic) DCS describes that which affects the neurologic, vestibular, or pulmonary systems. Neurologic involvement is most common among sport divers and can be caused by either spinal cord or cerebral involvement. Like pain-only DCS it is rapid in onset, with half of patients developing symptoms within 1 hour of surfacing and $90 \%$ reporting symptoms within 6 hours. The neurologic symptoms that present most often include numbness, dizziness, weakness, gait abnormality, and hypoesthesia (Table 3). ${ }^{10}$

Inner ear DCS (the "staggers") may be caused by bubble formation in the semicircular canals and presents as acute vertigo, nystagmus, tinnitus, and nausea with vomiting. Pulmonary DCS (the "chokes") is a rare condition probably caused by a

Table 3. Presenting Signs and Symptoms in Patients with Decompression Sickness

\begin{tabular}{lc}
\hline Sign or Symptom & Percentage \\
\hline Numbness & 59 \\
Pain & 55 \\
Dizziness & 27 \\
Extreme fatigue & 25 \\
Headache & 24 \\
Weakness & 23 \\
Nausea & 14 \\
Gait abnormality & 12 \\
Hypoesthesia & 10 \\
Visual Disturbance & 8 \\
Itching & 5 \\
\hline
\end{tabular}

Reproduced with permission from Neurologic Complications of Scuba Diving from the June 1, 2001 issue of American Family Physician. Copyright (C 2001 American Academy of Family Physicians. All Rights Reserved. 
Table 4. Summary of Diving-Related Conditions ${ }^{4,6,7,10,15,16}$

\begin{tabular}{|c|c|c|c|}
\hline Condition & Presentation & Dive History & Prevention/Treatment \\
\hline \multicolumn{4}{|l|}{ Barotrauma } \\
\hline Middle ear & $\begin{array}{l}\text { Acute ear pain, vertigo, tympanic } \\
\text { membrane rupture }\end{array}$ & Usually during descent & $\begin{array}{l}\text { Slow equalization on descent, } \\
\text { decongestants, consider } \\
\text { antibiotics for tympanic } \\
\text { membrane perforation }\end{array}$ \\
\hline Inner ear & $\begin{array}{l}\text { Acute vertigo, nausea, vomiting, } \\
\text { hearing loss }\end{array}$ & Usually during descent & $\begin{array}{l}\text { Bed rest, elevated head, } \\
\text { avoidance of Valsalva, } \\
\text { otolaryngology consult }\end{array}$ \\
\hline Sinus & Acute facial pain, epistaxis & Usually during descent & $\begin{array}{l}\text { Slow equalization on descent, } \\
\text { decongestants }\end{array}$ \\
\hline $\begin{array}{l}\text { Arterial gas } \\
\text { embolism }\end{array}$ & $\begin{array}{l}\text { Stupor, coma, focal weakness, } \\
\text { visual disturbances }\end{array}$ & $\begin{array}{l}\text { Immediately upon surfacing or } \\
\text { during ascent }\end{array}$ & $\begin{array}{l}\text { 100\% oxygen, supportive } \\
\text { care, US Navy Table } 6 \\
\text { Algorithm }\end{array}$ \\
\hline \multicolumn{4}{|l|}{$\begin{array}{l}\text { Decompression } \\
\text { Sickness }\end{array}$} \\
\hline Type I & $\begin{array}{l}\text { Poorly localized joint pain, rash, } \\
\text { itching }\end{array}$ & $\begin{array}{l}\text { Significant time at depth; } 50 \% \\
\text { develop symptoms within } 1 \\
\text { hour of surfacing, } 90 \% \\
\text { within } 6 \text { hours }\end{array}$ & $\begin{array}{l}\text { 100\% oxygen, supportive } \\
\text { care, US Navy Table } 6 \\
\text { Algorithm }\end{array}$ \\
\hline Type II & $\begin{array}{l}\text { Numbness, dizziness, weakness, } \\
\text { gait abnormality, hypoesthesia }\end{array}$ & $\begin{array}{l}\text { Significant time at depth; } 50 \% \\
\text { develop symptoms within } 1 \\
\text { hour of surfacing, } 90 \% \\
\text { within } 6 \text { hours }\end{array}$ & $\begin{array}{l}\text { 100\% oxygen, supportive } \\
\text { care, US Navy Table } 6 \\
\text { Algorithm }\end{array}$ \\
\hline
\end{tabular}

massive pulmonary gas embolism. This usually follows a rapid or uncontrolled ascent and presents with immediate substernal pain, cough, and cardiovascular shock resembling adult respiratory distress syndrome. ${ }^{16}$ The treatment for type II DCS is hydration, $100 \%$ oxygen, and immediate transport to a recompression facility for treatment under Table 6 algorithm of the US Navy Diving Manual. If the patient must be flown to a chamber, it is important to limit altitude to less than 1000 feet or use an aircraft that can be pressurized to sea level to prevent the exacerbation of symptoms.

\section{Decompression Illness}

Decompression Illness (DCI), a term that encompasses DCS and AGE, was introduced because treatment of either condition is recompression. However, distinction between the 2 is important for prognosis in future diving exposures. For clinical management, the greatest challenge may be to distinguish between DCI and nondiving conditions because of the vague nature of symptoms and because there are no specific diagnostic tests for DCI. However, diagnostic certainty is not required because divers with suspected DCI should be recompressed if there are no medical contraindications and a chamber is available (Table 4). ${ }^{17}$

\section{Flying After Diving}

Flying after diving deserves mention because many recreational dives take place away from home, which may involve air travel. The Diver's Alert Network (DAN) 2002 Consensus Guidelines for Flying After Recreational Diving (which apply to air dives followed by flights at cabin altitudes of 2000 to 8000 feet for divers without DCS symptoms) are summarized here: for a single no-decompression dive, one should wait at least 12 hours before flying; for multiple dives per day or multiple days of diving, 18 hours is suggested, and for any decompression dives, "substantially longer than 18 hours appears prudent." 18

\section{Common Medical Disorders and Diving}

There are several medical issues that may be contraindications to diving. The conditions covered here are some of the more controversial topics or ones that generate the most questions from primary care physicians. These include coronary artery disease, PFO, asthma, diabetes, spontaneous pneumothorax, and older age. Detailed fitness to dive considerations and a more comprehensive list of conditions can be found in Guidelines for Recreational Scuba Diver's Physical Examination ${ }^{19}$ or the Divers Alert Network webpage ${ }^{20}$ and in stan- 
dard texts. ${ }^{21,22}$ Alternatively, DAN is available for phone consultation during business hours at (800) 446-2671 or for emergency calls 24 hours a day, 7 days a week at (919) 684-8111. ${ }^{20}$

\section{Coronary Disease}

According to 2005 American Heart Association statistics, an estimated 16 million Americans have coronary heart disease-the single leading cause of death in the United States. This year an estimated 1.2 million Americans will suffer an acute coronary syndrome, and approximately 310,000 of them will die from the heart attack in an emergency department or without being hospitalized. ${ }^{23}$ DAN fatality surveillance data reveals that cardiac conditions are the number 2 cause of death, second only to drowning, in the 89 US and Canadian recreational divingrelated deaths in 2005 . Approximately $80 \%$ of fatalities were in people 40 years or older, and for those whose medical history was available, hypertension and heart disease were the most common conditions reported. ${ }^{13}$

Any physician caring for prospective divers must consider their patients' cardiac risk factors in light of the unique stresses diving puts on the heart. Aside from increased myocardial oxygen demands from swimming, preload is also increased because of immersion-induced increase in central venous return, whereas afterload is increased from coldinduced peripheral vasoconstriction. The Recreational Scuba Training Council, Undersea and Hyperbaric Medical Society (UHMS), and DAN recommend that divers over the age of 40 undergo risk assessment for coronary artery disease. Exercise stress testing may be recommended for asymptomatic divers with multiple cardiac risk factors. ${ }^{24}$ Routine screening would not be advised for young, low-risk divers because of the low positive predictive value of exercise stress testing in these individuals. ${ }^{25}$ Fitness to dive is optimal when a diver can reach a maximum capacity of 13 metabolic equivalents (METS) or stage 4 of the Bruce protocol. This peak capacity allows a diver to exercise comfortably at 8 to 9 METS. ${ }^{26}$ With increasing numbers of older divers, screening for coronary disease is essential for patients seeking medical clearance for sport diving. Individuals with known coronary artery disease, including those with previous heart attacks or revascularization procedures, may be cleared for low-stress sport diving after 6 to 12 months of healing and stabilization if a thorough cardiovascular evaluation including stress testing determines that age-adjusted cardiopulmonary fitness is not impaired. ${ }^{27}$

\section{Patent Foramen Ovale}

The foramen ovale is open during fetal life to allow for right to left shunting. For most people this opening is closed at birth by a flap that seals against the atrial septum. However, the flap is not sealed in approximately one third of the population and can open with changes in intrathoracic pressure. ${ }^{28}$ For years, there has been considerable controversy over the relationship between PFO and DCS. Ultrasound examination of divers has demonstrated that venous gas bubbles, which are common after diving and usually filtered by the pulmonary vasculature, can pass through a $\mathrm{PFO}$ and embolize the arterial circulation..$^{29}$ Shunting through a PFO may not be apparent at rest because left atrial pressure is usually greater than right atrial pressure almost entirely throughout the cardiac cycle. The exception to this may be during times of certain respiratory movements, such as the period after a Valsalva maneuver when a surge of venous blood transiently increases right atrial pressure. Actions such as straining to lift heavy objects (ie, scuba tanks after a dive) produce a similar effect on venous return.

Regardless of the improbability of paradoxical gas embolism, there have been several reports of possible associations between PFO and DCS. Causality is still unproven, but there seems to be an increased relative risk of developing DCS with a $\mathrm{PFO}$ versus without. The exact prevalence of $\mathrm{PFO}$ in divers with DCS is not known because of a combination of factors. Interpreting available data is complicated by imprecise diagnosis of DCS and poorly standardized methods of detecting PFO. ${ }^{30}$ The most widely quoted odds radio (OR) for serious DCS with PFO versus without PFO is 2.52 (95\%CI, $1.5-4.25)$ as determined by a meta-analysis published in $1998 .{ }^{31}$ This was with a reported per-dive incidence of DCS of 3.41 in 10,000 dives. In 2003, an extensive bibliographic review of 145 peer-reviewed journal articles related to PFO found no clear agreement regarding the role of PFO in DCS. ${ }^{32}$ From a combined analysis of the contrast transesophageal echocardiogram studies, an OR of 2.6 has been calculated for the development of DCS in divers with a PFO versus those 
without. ${ }^{30}$ Other authors have concluded that PFO increases the risk for DCS as much as 4.5 times. ${ }^{33}$ A more recent investigation into the functional and anatomic characteristics of $\mathrm{PFO}$ has yielded a possible higher risk subgroup. The unadjusted OR to develop DCS for divers with PFO was 5.5 (95\% CI $1.8-16.5)$. However, if stratifying by PFO characteristics, there was no statistically significant difference in risk for DCS for divers with PFO detected only during Valsalva than divers without PFO. There was a significant risk of divers with $\mathrm{PFO}$ at rest, with an OR of 24.8 (95\% CI 2.9-210.5). ${ }^{34}$

With this knowledge, we should consider our recommendations for diving and $\mathrm{PFO}$ based on the absolute increased risk. DCS in recreational divers is extremely rare, occurring after only $0.005 \%$ to $0.08 \%$ of dives. Presented differently, actual data from DAN's Project Dive Exploration recorded 4 cases of DCS in approximately 14,000 dives. ${ }^{13} \mathrm{Ev}-$ idence supports that the average recreational sport diver need not be screened for PFO. For those already diagnosed as having a PFO, this is not a contraindication for diving. Until we know more, a safe strategy would be to reduce the venous bubble load because it is the bubbles-not the PFO-that are the cause of DCS. This can be accomplished by avoiding dives that require decompression stops, by limiting bottom time, or by the appropriate use of oxygen-enriched breathing mixes. ${ }^{35}$

\section{Asthma}

More than 22 million Americans have asthma, which is roughly $7 \%$ of the total population. ${ }^{36}$ Several surveys have revealed the prevalence of active asthmatic disease among divers from $4 \%$ to $7 \% .{ }^{37-40}$ There is obvious theoretical concern for asthmatic divers. Pulmonary obstruction, air trapping, and hyperinflation that accompany an acute asthma attack would seemingly place the asthmatic diver at increased risk for pulmonary barotrauma. In addition, conditions such as cold and exercise serve as triggers for many asthmatics. Based on this, asthma had been traditionally considered an absolute contraindication to diving. ${ }^{9}$

Despite these facts and documented decrements in pulmonary function studies after diving, the evidence is equivocal for risk of pulmonary barotrauma or DCS among divers with asthma. A comprehensive review of the literature in 2003 found no epidemiologic evidence for an increased relative risk of pulmonary barotrauma, DCS, or death among divers with asthma. ${ }^{41}$ However, this information may be biased because it accounts only for asthmatics with mild disease who have chosen to dive against medical advice. The actual risk for all asthmatics is probably higher than what is shown in published studies. ${ }^{42}$

With such vast differences among patients with respect to precipitating factors, pulmonary function, and degree of airway obstruction and reversibility, it is difficult to consider asthma as a single disease when assessing fitness to dive. Rather, this condition demands individualized consideration based on each specific diver's history and disease syndrome. ${ }^{9}$ There are several published guidelines with a variety of recommendations for diving with asthma. In Australia, all divers with asthma must pass spirometry before certification, but in the United Kingdom, well-controlled asthmatics (excluding cold-, exercise-, or emotion-induced asthmatics) may dive as long as they do not require a bronchodilator within 48 hours. ${ }^{43,44}$ Among experts and other major diving organizations, the consensus is that lung function must be normal before an asthmatic can dive. Carefully selected mild to moderate, well-controlled asthmatics with normal screening spirometry can be considered candidates for diving per recommendations by the Recreational Scuba Training Council and the UHMS. ${ }^{45}$ Spirometry should be normal before and after exercise testing. Medication used to maintain normal spirometry is not a contraindication to diving. Inhalation challenge tests, including methacholine or hypertonic saline, are not recommended. ${ }^{19}$

\section{Diabetes}

Individuals with diabetes mellitus (DM) who are treated with insulin or oral hypoglycemic agents are at increased risk for hypoglycemia during or after exercise. Because of the potential for underwater hypoglycemic events, diabetics have historically been prohibited from diving. ${ }^{46}$ The Recreational Scuba Training Council, UHMS, and DAN consider diabetes a severe risk condition in accordance with the Scuba Schools International guidelines. ${ }^{19}$ This guideline warns that a rapidly changing level of consciousness associated with hypoglycemia can contribute to drowning and specifies that "diving is therefore generally contraindicated, unless associated with a specialized program that addresses these 
issues." ${ }^{19}$ Because the Diabetes and Diving Committee (joint UHMS/American Diabetes Association) established the first fitness to dive criteria in 1994 for physically fit diabetics with well-controlled disease, multiple studies have demonstrated that select diabetics can safely participate in recreational diving and that evidence is lacking for a widespread ban on diving for all diabetics. ${ }^{46}$ However, expert recommendations support holding diabetic divers to a very high standard of physical fitness and experience in diabetes management, including monitoring daily glucose patterns and the effects of strenuous exercise and excluding divers with any significant systemic diabetic sequelae, recent history of hypoglycemia, or poorly controlled blood glucose. ${ }^{24,46}$ A workshop jointly sponsored by the UHMS and DAN in 2005 published guidelines for diabetes and recreational diving. These guidelines stipulate that adults with DM may qualify as fit to dive during their physician's annual review if they have been on a stable dose of insulin for 1 year or oral hypoglycemic agents for 3 months; have a glycosylated hemoglobin level of $\leq 9 \%$; have had no significant episodes of hypo- or hyperglycemia for 1 year; have no secondary complications of DM; and have no hypoglycemia unawareness. In addition, these guidelines provide scope of diving limitations and recommendations for glucose management on the day of diving. ${ }^{47}$

\section{Spontaneous Pneumothorax}

Some individuals have weak areas (blebs) in the pleural lining of the lung that can rupture without provocation, resulting in pneumothorax. Approximately half of those who suffer a spontaneous pneumothorax are likely to have another because they usually have multiple pleural blebs, which are all prone to leak at one time or another. ${ }^{48}$ Because there is evidence that divers who have experienced spontaneous pneumothorax are at greater risk of pneumothorax or gas embolism while diving, most dive physicians recommend that individuals who have experienced spontaneous pneumothorax should not dive. ${ }^{10}$ In diving, these blebs or bullae in the lungs predispose a diver to pulmonary barotrauma because they are weaker than normal lung tissue, empty their air slowly during exhalation, and can build up pressure during ascent causing rupture. Computed tomography scanning may be recommended to detect blebs; however, even if imaging shows no evidence of underlying lung disease, patients with a history of spontaneous pneumothorax are recommended not to dive under any circumstances. ${ }^{49}$ Even if a surgical procedure designed to prevent recurrent spontaneous pneumothorax, such as pleurodesis, has been used, recommendations remain to avoid diving, although individual divers have returned to diving without incident after surgical blebectomy. ${ }^{19}$

\section{The Elderly and Diving}

With growing physical activity among older Americans, primary care physicians are being asked with increased frequency to evaluate their elderly patients for fitness to dive. Similarly, the diving population is aging along with the US population at large. The following evidence can support recommendations for older patients who wish to participate in sport diving. There is no formal age limitation for recreational scuba diving. Recommendations for diving in the elderly are based on the presence of acute or chronic illness and especially on the physical conditioning of the individual. Physical capacity is known to decline with age, yet, as we know, there are many older individuals who have attained a higher level of fitness than many of their younger counterparts. However, there are some basic physiologic responses to aging that should be considered when reviewing older patients' fitness to dive. ${ }^{50}$

Known cardiovascular changes with age include increases in blood pressure and peripheral vascular resistance and decreases in oxygen update, work capacity, and maximal heart rate. Some of these cardiovascular parameters that have been thought to change with age may actually be associated more with fitness level. ${ }^{51}$ In addition, as stated earlier, coronary artery disease, higher rates of which are seen among the elderly, is a major contributor to diving-related deaths in North America. Therefore, emphasis is placed on assessing physical capacity and screening for coronary disease during evaluation for fitness to dive. As previously mentioned, individuals aged 40 or older should undergo risk assessment for coronary artery disease, which may require formal exercise testing. A maximum capacity of 13 METS is the suggested criteria for stress testing to allow a diver to swim comfortably with diving gear in a 1 -knot current expending 8 to 9 METS. $^{19}$ Other physiologic changes with age include breathing difficulties from increased dead space, glucose intolerance, heat and cold intoler- 
ance, decreased range of motion from changes in collagen structure, and alterations of neurological function.

Because many diving accidents are caused by inadequate training, poor physical conditioning, and human error, all of these factors must be considered for a given individual before recommending diving. Any combination of minor physical deficits in an older diver may contribute to an increased risk for diving injuries or mishaps. With careful evaluation, it is certainly reasonable for some elderly people in good health to undertake safe recreational diving. It would be prudent, however, to recommend a diving program that may not be as rigorous as programs recommended for their younger counterparts. ${ }^{50}$

\section{Conclusion}

Scuba diving is an increasingly popular recreational sport. An understanding of the pathophysiology, injury patterns, and treatment for both common and life-threatening diving injuries is critical for the primary care physician to advise, diagnose, and treat the recreational diver.

We would like to thank Robert Oh, MD, MPH; Travis Deaton, MD; and C. David Sutton, MD, for their critical review of this article.

\section{References}

1. Professional Association of Diving Instructors. Worldwide certification history. Available at: http:// www.padi.com/padi/en/footerlinks/certhistorynum. aspx. Accessed February 18, 2008.

2. Scubamed. Underwater medicine 2008. Dominica. January 12-19. Available at: http://www.scubamed. com/tuum_prg.htm. Accessed October 26, 2008.

3. Taylor L. Diving physics. In: Bove AA, Davis JC, eds. Diving medicine. 4th ed. Philadelphia, PA: Saunders; 2004:11-35.

4. Hunter SE, Farmer JC. Ear and sinus problems in diving. In: Bove AA, Davis JC, eds. Diving medicine. 4th ed. Philadelphia, PA: Saunders; 2004:431-59.

5. Clenney TL, Lassen LF. Recreational scuba diving injuries. Am Fam Physician 1996;53:1761-6.

6. Parell GJ, Becker GD. Neurological consequences of scuba diving with chronic sinusitis. Laryngoscope 2000;110:1358-60.

7. Kay E. Doc's Diving Medicine. Prevention of middle ear barotrauma. Available at: http://faculty.washington. edu/ekay/. Accessed February 10, 2008.

8. Cheshire WP. Headache and facial pain in scuba divers. Curr Pain Headache Rep 2004;8:315-20.
9. Neuman TS. Pulmonary barotrauma. In: Bove AA, Davis JC, eds. Diving medicine. 4th ed. Philadelphia, PA: Saunders; 2004:185-94.

10. Newton HB. Neurologic complications of scuba diving. Am Fam Physician 2001;63:2211-8, 2225-6.

11. Bove AA. Medical aspects of sport diving. Med Sci Sports Exerc 1996;28:591-5.

12. Vann RD. Mechanisms and risks of decompression. In: Bove AA, Davis JC, eds. Diving medicine. 4th ed. Philadelphia, PA: Saunders; 2004:127-64.

13. Divers Alert Network Annual Diving Report 2007. Durham, NC: Divers Alert Network, 2007.

14. Wilmshurst PT, Pearson MJ, Walsh KP, et al. Relationship between right-to-left shunts and cutaneous decompression illness. Clin Sci 2001;100:53942 .

15. Moon RE. Treatment of decompression illness. In: Bove AA, Davis JC, eds. Diving medicine. 4th ed. Philadelphia, PA: Saunders; 2004:195-217.

16. Francis TJ, Mitchell SJ. Pathophysiology of decompression sickness. In: Bove AA, Davis JC, eds. Diving medicine. 4th ed. Philadelphia, PA: Saunders; 2004: 165-83.

17. Vann RD, Moon RE, Freiberger JJ, et al. Decompression illness diagnosis and decompression study design. Aviat Space Environ Med 2008;79:797-8.

18. Sheffield PJ, Vann RD, eds. DAN Flying After diving workshop proceedings. Durham, NC: Divers Alert Network; 2004.

19. Scuba Schools International. Guidelines for recreational scuba diver's physical examination; 2002:1-4. Available at: http://www.scubaland.com/Files/PDF/ Medical\%20Exam\%20Guidelines.pdf. Accessed October 26, 2008.

20. Divers Alert Network. [Homepage.] Available at: https://www.diversalertnetwork.org/default.aspx. Accessed October 26, 2008.

21. Bove AA. Medical evaluation for sport diving. In: Bove AA, Davis JC, eds. Diving medicine. 4th ed. Philadelphia, PA: Saunders; 2004:519-32.

22. Brubakk AO, Neuman TS, eds. Bennett and Elliott's Physiology and Medicine of Diving. 5th ed. London: Saunders; 2003.

23. American Heart Association. Cardiovascular disease statistics. Available at: http://www.americanheart. org/presenter.jhtml?identifier $=4478$. Accessed February $10,2008$.

24. Harrison D, Lloyd-Smith R, Khazei A, Hunte G, Lepawsky M. Controversies in the medical clearance of recreational scuba divers: updates on asthma, diabetes mellitus, coronary artery disease and patent foramen ovale. Curr Sports Med Rep 2005;4:27581.

25. Lauer M, Froelicher ES, Williams M, Kligfield P. Exercise testing in asymptomatic adults: a statement for professionals from the American Heart Association Council on Clinical Cardiology, Subcommittee 
on Exercise, Cardiac Rehabilitation, and Prevention. Circulation 2005;112:771-6.

26. Pendergast DR, Tedesco M, Nawrocki DM, Fisher NM. Energetics of underwater swimming with SCUBA. Med Sci Sports Exerc 1996;28:573-80.

27. Divers Alert Network, Caruso JL. Diving medicine articles. Cardiovascular fitness and diving. Available at: http://www.diversalertnetwork.org/medical/articles/ article.asp? articleid=11. Accessed February 10, 2008.

28. Lynch JJ, Schuchard GH, Gross CM, Wann LS. Prevalence of right-to-left shunting in a healthy population: detection by valsalva maneuver contrast echocardiography. Circulation 1984;59:379-84.

29. Moon RE. Camporesi EM, Kisslo JA. Patent foramen ovale and decompression sickness in divers. Lancet 1989;1:513-4.

30. Germonpre P. Patent foramen ovale and diving. Cardiol Clin 2005;23:97-104.

31. Bove AA. Risk of decompression sickness with a patent foramen ovale. Undersea Hyperb Med 1998; 25:175-8.

32. Foster PP, Boriek AM, Butler BD, Gernhardt ML, Bove AA. Patent foramen ovale and paradoxical systemic embolism: a bibliographic review. Aviat Space Environ Med 2003;74(6 Pt 2):B1-64.

33. Schwerzmann M, Seiler C, Lipp E, et al. Relation between directly detected patent foramen ovale and ischemic brain lesions in sport divers. Ann Intern Med 2001;134:21-4.

34. Cartoni D, De Castro S, Valente G, et al. Identification of professional scuba divers with patent foramen ovale at risk for decompression illness. Am J Cardiol 2004;94:270-3.

35. Moon RE, Bove AA. Transcatheter occlusion of patent foramen ovale: A prevention for decompression illness? Undersea Hyperb Med 2004;31:271-4.

36. National Heart, Lung, and Blood Institute. Guidelines for the diagnosis and management of asthma (EPR-3). Available at: http://www.nhlbi.nih.gov/ guidelines/asthma/. Accessed February 18, 2008.

37. Neuman TS, Powers AT, Osborn DE. The prevalence of asthma, diabetes and epilepsy in a population of divers. Undersea Biomed 1988;15(Suppl): 62-3.

38. Corson KS, Moon RE, Nealen ML, et al. A survey of diving asthmatics. Undersea Biomed Res 1992; 19(Suppl):18-9.

39. Bove AA, Neuman TS, Kelsen S, et al. Observations on asthma in the recreational diving population. Undersea Biomed Res 1992;19(Suppl):18.

40. Report Project Dive Exploration. Divers Alert Network Annual Diving Report 2007 Edition, based on 2005 data. Durham, NC: Divers Alert Network, 2007.

41. Koehle M, Lloyd-Smith R, McKenzie D, Taunton J. Asthma and recreational scuba diving: a systematic review. Sports Med 2003;33:109-16.

42. Divers Alert Network, de Lisle Dear G. Asthma and diving. Available at: http://www.diversalertnetwork.org/medical/articles/article.asp?articleid=22. Accessed February 18, 2008.

43. South Pacific Underwater Medicine Society, Gorman D, Veale A. SPUMS policy on asthma and fitness for diving. Available at: http://www.spums.org. au/spums_policy/spums_policy_on_asthma_and_ fitness_for_diving. Accessed on: February 18, 2008.

44. British Sub Aqua Club. Medical information. Asthma. Available at: www.bsac.com/core/core_picker/ download.asp? $i d=10093 \&$ filetitle $=$ Asthma. Accessed on: February 18, 2008.

45. Elliott DH, ed. Are asthmatics fit to dive? Kensington, MD: Undersea and Hyperbaric Medical Society; 1996.

46. Scott DH, Marks AD. Diabetes and Diving. In: Bove AA, Davis JC, eds. Diving medicine. 4th ed. Philadelphia, PA: Saunders; 2004:507-18.

47. Pollock NW, Uguccioni DM, Dear GdeL, eds. Diabetes and recreational diving: guidelines for the future. Proceedings of the Undersea Hyperbaric Medical Society/Divers Alert Network workshop, June 19, 2005. Durham, NC: Divers Alert Network; 2005.

48. Bove AA. Diving medicine. Asthma and diving. Available at: http://www.scubamed.com/divmed.htm. Accessed February 18, 2008.

49. Divers Alert Network, Moon RE. Scanning for blebs. Available at: http://www.diversalertnetwork. org/medical/articles/article.asp? articleid $=40$. Accessed February 18, 2008.

50. Bove AA. Diving in the elderly and the young. In: Bove AA, Davis JC, eds. Diving medicine. 4th ed. Philadelphia, PA: Saunders; 2004:411-20.

51. Mazzeo RS, Cavanagh P, Evans WJ, et al. ACSM position stand on exercise and physical activity for older adults. Med Sci Sports Exerc 1998;30:9921008. 